medRxiv preprint doi: https://doi.org/10.1101/2020.11.25.20229088; this version posted February 12, 2021. The copyright holder for this preprint (which was not certified by peer review) is the author/funder, who has granted medRxiv a license to display the preprint in perpetuity.

It is made available under a CC-BY 4.0 International license .

\title{
Use of dialysis, tracheostomy, and extracorporeal membrane oxygenation among 842,928 patients hospitalized with COVID-19 in the United States
}

\author{
Edward Burn*1,2, Anthony G. Sena*3,4, Albert Prats-Uribe ${ }^{2}$, Matthew Spotnitz ${ }^{5}$, Scott
} DuVall ${ }^{6,7}$, Kristine E. Lynch ${ }^{6,8}$, Michael E. Matheny ${ }^{9,10}$, Fredrik Nyberg ${ }^{11}$, Waheed-Ul-Rahman Ahmed ${ }^{12,13}$, Osaid Alser ${ }^{14}$, Heba Alghoul ${ }^{15}$, Thamir Alshammari ${ }^{16}$, Lin Zhang ${ }^{17,18}$, Paula Casajust $^{19}$, Carlos Areia20, Karishma Shah ${ }^{12}$, Christian Reich ${ }^{21}$, Clair Blacketer $^{3}$, Alan Andryc ${ }^{3}$, Stephen Fortin ${ }^{3}$, Karthik Natarajan ${ }^{5}$, Mengchun Gong ${ }^{22}$, Asieh Golozar ${ }^{23,24}$, Daniel Morales ${ }^{25}$, Peter Rijnbeek ${ }^{4}$, Vignesh Subbian ${ }^{26}$, Elena Roel ${ }^{1}$, Martina Recalde ${ }^{1,27}$, Jennifer C.E. Lane ${ }^{2}$, David Vizcaya ${ }^{28}$, Jose D. Posada ${ }^{29}$, Nigam H. Shah ${ }^{29}$, Jitendra Jonnagaddala ${ }^{30}$, Lana Yin Hui Lai $^{31}$, Francesc Xavier Avilés-Jurado ${ }^{32,33}$, George Hripcsak ${ }^{5}$, Marc A. Suchard ${ }^{34}$, Otavio T. Ranzani $^{35,36}$, Patrick Ryan ${ }^{3,37}$, Daniel Prieto-Alhambra ${ }^{2} \neq$, Kristin Kostka ${ }^{21}+$, Talita DuarteSalles ${ }^{1+}$

${ }^{1}$ Fundació Institut Universitari per a la recerca a l'Atenció Primària de Salut Jordi Gol i Gurina (IDIAPJGol), Barcelona, Spain, ${ }^{2}$ Centre for Statistics in Medicine, NDORMS, University of Oxford, ${ }^{3}$ Janssen Research \& Development, Titusville, NJ, USA, ${ }^{4}$ Department of Medical Informatics, Erasmus University Medical Center, Rotterdam, The Netherlands, ${ }^{5}$ Department of Biomedical Informatics, Columbia University, New York, NY, US, ${ }^{6}$ Department of Veterans Affairs, Salt Lake City, UT, US, ${ }^{7}$ University of Utah School of Medicine, Salt Lake City, UT, US, ${ }^{8}$ Department of Internal Medicine, University of Utah School of Medicine, Salt Lake City, UT, USA, ${ }^{9}$ Tennessee Valley Healthcare System, Veterans Affairs Medical Center, Nashville, TN, USA, ${ }^{10}$ Department of Biomedical Informatics, Vanderbilt University Medical Center, Nashville, TN, USA, ${ }^{11}$ School of Public Health and Community Medicine,, Institute of Medicine, Sahlgrenska Academy, University of Gothenburg, Gothenburg, Sweden, ${ }^{12}$ Nuffield Department of Orthopaedics, Rheumatology, and Musculoskeletal Sciences, University of Oxford, Botnar Research Centre, Windmill Road, Oxford, OX3 7LD, UK, ${ }^{13}$ College of Medicine and Health, University of Exeter, St Luke's Campus, Heavitree Road, Exeter, EX1 2LU, UK, ${ }^{14}$ Massachusetts General Hospital, Harvard Medical School, Boston, USA, ${ }^{15}$ Faculty of Medicine, Islamic University of Gaza, Palestine, ${ }^{16}$ Medication Safety Research Chair, King Saud University, Riyadh, Saudi Arabia, ${ }^{17}$ School of Population Medicine and Public Health, Peking Union Medical College and Chinese Academy of Medical Sciences, ${ }^{18}$ School of Population and Global Health, The University of Melbourne, ${ }^{19}$ Real-World Evidence, Trial Form Support, Barcelona, Spain, ${ }^{20}$ Nuffield Department of Clinical Neurosciences, University of Oxford, ${ }^{21}$ Real World Solutions, IQVIA, Cambridge, MA USA, ${ }^{22}$ Southern Medical University, Guangzhou, China, ${ }^{23}$ Regeneron Pharmaceuticals, NY US, ${ }^{24}$ Johns Hopkins Bloomberg School of Public Health, Baltimore, MD US, ${ }^{25}$ Division of Population Health and Genomics, University of Dundee, ${ }^{26}$ College of Engineering, The University of Arizona, Tucson, Arizona, USA, ${ }^{27}$ Universitat Autònoma de Barcelona, Spain, ${ }^{28}$ Bayer Pharmaceuticals, Sant Joan Despi, Spain, ${ }^{29}$ Department of Medicine, Stanford University, ${ }^{30}$ School of Public Health and Community Medicine, UNSW Sydney, ${ }^{31}$ Division of Cancer Sciences, School of Medical Sciences, University of Manchester ${ }^{32}$ Otorhinolaryngology HeadNeck Surgery Department, Hospital Clínic, IDIBAPS Universitat de Barcelona, Villarroel 170, 08036, Barcelona, Spain, ${ }^{33}$ Agència de Gestió d'Ajuts Universitaris i de Recerca (AGAUR, Generalitat de Catalunya, 2017-SGR-01581, Barcelona, Spain, ${ }^{34}$ Department of Biostatistic, UCLA Fielding School of Public Health, University of California, Los Angeles, ${ }^{35}$ Barcelona

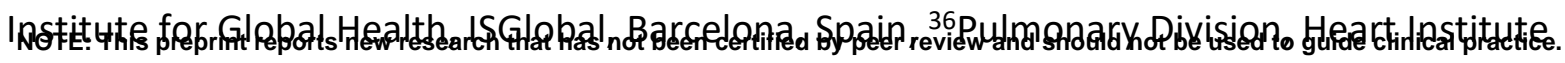


medRxiv preprint doi: https://doi.org/10.1101/2020.11.25.20229088; this version posted February 12, 2021. The copyright holder for this preprint (which was not certified by peer review) is the author/funder, who has granted medRxiv a license to display the preprint in

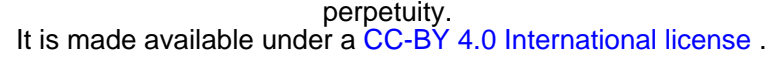

(InCor, Hospital das Clinicas, Faculdade de Medicina, Universidade de Sao Paulo, Sao Paulo, Brazil ${ }^{37}$ Columbia University, New York, NY, US

*joint first authors, ¥corresponding author, †joint senior authors

\section{Abstract \\ Objective}

To estimate the proportion of patients hospitalized with COVID-19 who undergo dialysis, tracheostomy, and extracorporeal membrane oxygenation (ECMO).

Design

A network cohort study.

Setting

Seven databases from the United States containing routinely-collected patient data:

HealthVerity, Premier, IQVIA Hospital CDM, IQVIA Open Claims, Optum EHR, Optum SES, and VA-OMOP.

\section{Patients}

Patients hospitalized with a clinical diagnosis or a positive test result for COVID-19.

\section{Interventions}

Dialysis, tracheostomy, and ECMO.

\section{Measurements and Main Results}

842,928 patients hospitalized with COVID-19 were included $(22,887$ from HealthVerity, 77,853 from IQVIA Hospital CDM, 533,997 from IQVIA Open Claims, 36,717 from Optum EHR, 4,336 from OPTUM SES, 156,187 from Premier, and 10,951 from VA-OMOP). Across the six databases, 35,192 (4.17\% [95\% Cl: $4.13 \%$ to $4.22 \%]$ ) patients received dialysis, 6,950 ( $0.82 \%$ [0.81\% to $0.84 \%]$ ) had a tracheostomy, and $1,568(0.19 \%$ [ $95 \% \mathrm{Cl}: 0.18 \%$ to $0.20 \%$ ]) patients underwent ECMO over the 30 days following hospitalization. Use of ECMO was more common among patients who were younger, male, and with fewer comorbidities. Tracheostomy was broadly used for a similar proportion of patients regardless of age, sex, or comorbidity. While dialysis was generally used for a similar proportion among younger and older patients, it was more frequent among male patients and among those with chronic kidney disease.

\section{Conclusion}

Use of dialysis among those hospitalized with COVID-19 is high at around 4\%. Although less than one percent of patients undergo tracheostomy and ECMO, the absolute numbers of patients who have undergone these interventions is substantial. 
medRxiv preprint doi: https://doi.org/10.1101/2020.11.25.20229088; this version posted February 12, 2021. The copyright holder for this preprint (which was not certified by peer review) is the author/funder, who has granted medRxiv a license to display the preprint in

It is made available under a CC-BY 4.0 International license.

\section{Background}

Treatment of patients hospitalized with coronavirus disease 2019 (COVID-19) may involve a range of medical interventions. Three distinct invasive interventions that can be readily identified in routinely collected health data and have been used in the treatment of severe COVID-19 are extracorporeal membrane oxygenation (ECMO), tracheostomy, and dialysis. For those patients with refractory hypoxemia, ECMO provides an advanced organ support alternative. ${ }^{1}$ Tracheostomy gives a means of facilitating long-term mechanical ventilation among critically ill patients. ${ }^{2}$ Additionally, the wide-ranging effects of COVID-19 are also seen with the need for dialysis to support kidney function among patients with an acute kidney injury. ${ }^{3,4}$ There remains uncertainty around the optimal use of each of these interventions among patients with COVID-19. For those patients who do undergo them, the use of these interventions can be taken to indicate severe disease and, for survivors, will likely be associated with long-term morbidity. ${ }^{1,5-7}$

Evidence on the extent of the use of invasive interventions among individuals hospitalized with COVID-19 can help improve our understanding of patient outcomes, inform healthcare resource planning, and provide an indication of some of the long-term consequences of the disease. Our objective in this study was therefore to describe the use of ECMO, tracheostomy, and dialysis among patients hospitalized with COVID-19.

\section{Methods}

Seven large databases containing routinely-collected health care data from the United States (US) provided the basis for the analysis, with each mapped to the Observational Medical Outcomes Partnership Common Data Model (OMOP CDM). The HealthVerity database contains information on individuals with a test for COVID-19 with linkage to medical claims and pharmacy data. The Premier Healthcare Database (Premier) includes clinical coding, hospital cost, and patient billing data. The IQVIA Hospital charge data masters (CDM) includes data from resource management software within short-term, acute-care and non-federal hospitals, while IQVIA Open Claims captures open, preadjudicated medical claims. Optum ${ }^{\circledR}$ de-identified COVID-19 Electronic Health Record dataset (Optum EHR) Dataset represents Optum's EHR data, while Optum ${ }^{\circledR}$ De-Identified Clinformatics ${ }^{\circledR}$ Data Mart Database - Socio-Economic Status Database (Optum SES) is an 
medRxiv preprint doi: https://doi.org/10.1101/2020.11.25.20229088; this version posted February 12, 2021. The copyright holder for this preprint (which was not certified by peer review) is the author/funder, who has granted medRxiv a license to display the preprint in

It is made available under a CC-BY 4.0 International license .

adjudicated administrative health claims database. The Department of Veterans Affairs OMOP (VA-OMOP) database reflects the national Department of Veterans Affairs health care system. This study is part of the ongoing Observational Health Data Sciences and Informatics (OHDSI) Characterizing Health Associated Risks, and Your Baseline Disease In SARS-COV-2 (CHARYBDIS) project, with the findings presented here based on data submitted as of $1^{\text {st }}$ October 2020.

Patients hospitalized with COVID-19 were identified in the same way as in a previous study using the OMOP CDM. ${ }^{8}$ COVID-19 hospitalizations ran up to March 2020 in OPTUM SES, June 2020 in HEALTHVERITY and VA-OMOP, July 2020 in IQVIA Hospital CDM, September in Premier, and October 2020 in IQVIA Open Claims and OPTUM EHR. The characteristics of study participants up to and including each individuals' date of hospitalization (index date) were extracted, including age, sex and comorbidities (asthma, autoimmune condition, chronic kidney disease [CKD], chronic obstructive pulmonary disease [COPD], type 2 diabetes, hypertension, and obesity).

Instances of ECMO, tracheostomy, and dialysis were identified between the index date and up to 30 days following the date. Instances of dialysis were also identified in the interval from 30 days to 1 day prior to index date. The proportion of patients who underwent the interventions was calculated for each database, and stratified by age (65 or younger, and over 65), sex, and comorbidities of interest.

The entire list of definitions used to identify patients with a COVID-19 hospitalization, their comorbidities, and interventions of interest can be explored at https://github.com/ohdsistudies/Covid19CharacterizationCharybdis/blob/master/documents/CharybdisPhenotypeLib rary.csv.

\section{Results}

A total of 842,928 patients hospitalized with COVID-19 were included. Their baseline characteristics are described in Table 1.

Across the seven databases, $1,568(0.19 \%$ [95\% $\mathrm{Cl}: 0.18 \%$ to $0.20 \%)]$ patients underwent ECMO. The proportion of patients who underwent ECMO ranged from $0.10 \%(0.06 \%$ to $0.15 \%)$ in HealthVerity to as high as $0.26 \%$ (0.20\% to $0.31 \%)$ in OPTUM EHR. ECMO was 
medRxiv preprint doi: https://doi.org/10.1101/2020.11.25.20229088; this version posted February 12, 2021. The copyright holder for this preprint (which was not certified by peer review) is the author/funder, who has granted medRxiv a license to display the preprint in perpetuity.

more often seen among patients under 65 and males, Figure 1. In IQVIA Open Claims, for example, $0.33 \%$ ( $0.30 \%$ to $0.35 \%$ ) of those under 65 underwent ECMO while only $0.03 \%$ $(0.02 \%$ to $0.03 \%)$ of those 65 or older did so, and $0.22 \%(0.21 \%$ to $0.24 \%)$ of men received the intervention compared to $0.12 \%(0.10 \%$ to $0.13 \%)$ of women. ECMO was generally used less for most of the comorbidities considered (Figure 2).

In total, 6950 (0.82\% [0.81\% to $0.84 \%])$ had a tracheostomy, with this proportion ranging from $0.28 \%(0.12 \%$ to $0.43 \%)$ in OPTUM SES to $1.05 \%$ (1.00\% to $1.10 \%)$ in Premier. Use of tracheostomy was broadly similar by age and sex, Figure 1, and by comorbidity, Figure 2, across databases.

A total of 35,192 (4.17\% [4.13\% to $4.22 \%$ ]) patients received dialysis over the 30 days following hospitalization across the six databases, ranging from $2.61 \%$ (2.13\% to $3.08 \%)$ in OPTUM SES to $6.93 \%$ (6.80\% to $7.06 \%$ ) in Premier. In comparison, in the 30 days prior to hospitalization, $0.6 \%$ of patients in VA-OMOP, $0.5 \%$ in OPTUM EHR, and $1.5 \%$ in IQVIA Open Claims were seen to have undergone dialysis. Use of dialysis was similar by age but was more common among men, Figure 1. In IQVIA Open Claims, for example, 3.6\% (3.6\% to $3.7 \%$ ) of men underwent dialysis while $2.5 \%$ (2.4\% to $2.5 \%$ ) of women did so. Dialysis was more common among those with pre-existing CKD, Figure 2. In Premier, 19.6\% (19.1\% to 20.1\%) of those with CKD underwent dialysis after being hospitalized compared to $4.6 \%$ (4.5\% to $4.7 \%)$ for those without. Dialysis was also typically slightly more common for various other comorbidities (Figure 2).

\section{Discussion}

Prior to COVID-19, ECMO, tracheostomy, and dialysis for acute renal failure have each been associated with poor long-term health outcomes. ${ }^{1,5-7}$ While continued follow-up is required to observe the long-term outcomes of the patients hospitalized with COVID-19 and underwent such interventions, it can be expected that those individuals that survived their hospitalization will face long-term morbidity and require ongoing care.

Around $4 \%$ of patients hospitalized with COVID-19 identified in this study were seen to have undergone dialysis between the day of their admission and 30 days later. This is broadly in line with the findings of a multi-center study across 12 hospitals in New York City, where around $4 \%$ of 5,700 patients hospitalized with COVID-19 received kidney replacement 
medRxiv preprint doi: https://doi.org/10.1101/2020.11.25.20229088; this version posted February 12, 2021. The copyright holder for this preprint (which was not certified by peer review) is the author/funder, who has granted medRxiv a license to display the preprint in

It is made available under a CC-BY 4.0 International license .

therapy. ${ }^{9}$ Higher use has though been seen for the Mount Sinai hospital system in New York City, where $9 \%$ of 3,993 hospitalized patients underwent dialysis, ${ }^{10}$ and among the first 1,000 patients hospitalized in the NewYork-Presbyterian/Columbia University Irving Medical Center, where $14 \%$ received dialysis. ${ }^{11}$ These higher rates might reflect differences in patient populations, if those admitted in these centers had particularly severe disease, or differences in treatment protocols. Given their rare occurrence, relatively few studies have reported on the use of tracheostomy and ECMO among COVID-19 patients. One of the aforementioned studies showed the use of ECMO to be $0.6 \%,{ }^{11}$ which is slightly higher than seen in this study, which likely reflects both the setting and the severity of the patients seen at this center.

In this study we have focused on three invasive interventions which could be readily identified in each of the databases. The consistency of our results across databases is reassuring. However, it is possible that use of interventions may be underestimated if not all interventions used are unambiguously reported. This, for example, may be the concern for dialysis which when performed in intensive care may not have been recorded with a specific code, but rather billed as part of overall intensive care stay. In addition, among the databases with limited prior observation time, comorbidities can also be expected to be underreported, as can be seen with obesity in particular in HEALTHVERITY and Premier. Further interventions are of interest but were beyond the scope of this study. In particular, while we also assessed the feasibility of summarizing the use of mechanical ventilation, this was seen to have heterogeneous reporting across databases.

The findings from this study underline the severity of disease among hospitalized individuals with COVID-19. The long-term consequences for individuals who underwent the interventions and were discharged alive are likely to be substantial, both in terms of morbidity for the patients and economic burden for both patients and the health system, with individuals likely to have long-term health care needs. 
medRxiv preprint doi: https://doi.org/10.1101/2020.11.25.20229088; this version posted February 12,2021 . The copyright holder for this preprint (which was not certified by peer review) is the author/funder, who has granted medRxiv a license to display the preprint in

It is made available under a CC-BY 4.0 International license .

\section{References}

1. Munshi, L. et al. Venovenous extracorporeal membrane oxygenation for acute respiratory distress syndrome : a systematic review and meta-analysis. Lancet Respir. $7,163-172$

2. McGrath, B. A. et al. Tracheostomy in the COVID-19 era: global and multidisciplinary guidance. Lancet Respir. Med. 8, 717-725 (2020).

3. Ronco, C., Reis, T. \& Husain-Syed, F. Management of acute kidney injury in patients with COVID-19. Lancet Respir. Med. 8, 738-742 (2020).

4. Ronco, C. \& Reis, T. Kidney involvement in COVID-19 and rationale for extracorporeal therapies. Nat. Rev. Nephrol. 16, 308-310 (2020).

5. Cinotti, R. et al. Tracheostomy and long-term mortality in ICU patients undergoing prolonged mechanical ventilation. PLoS One 14, e0220399 (2019).

6. Vargas, M. et al. Mortality and long-term quality of life after percutaneous tracheotomy in Intensive Care Unit . A prospective observational study 84, 1024$1031(2018)$.

7. Lo, L. J. et al. Dialysis-requiring acute renal failure increases the risk of progressive chronic kidney disease. Kidney Int. 76, 893-899 (2009).

8. Burn, E. et al. Deep phenotyping of 34,128 adult patients hospitalised with COVID-19 in an international network study. Nat. Commun. 11, 5009 (2020).

9. Richardson, S. et al. Presenting Characteristics, Comorbidities, and Outcomes Among 5700 Patients Hospitalized With COVID-19 in the New York City Area. JAMA (2020). doi:10.1001/jama.2020.6775

10. Chan, L. et al. AKI in Hospitalized Patients with COVID-19. J. Am. Soc. Nephrol. (2020). doi:10.1681/ASN.2020050615

11. Argenziano, M. G. et al. Characterization and clinical course of 1000 patients with coronavirus disease 2019 in New York: retrospective case series. BMJ 369, (2020). 
Table 1. Characteristics of study cohorts in included databases.

\begin{tabular}{|c|c|c|c|c|c|c|c|}
\hline & HEALTHVERITY & Hospital CDM & Open Claims & OPTUM EHR & OPTUM SES & Premier & VA-OMOP \\
\hline$N$ & 22,887 & 77,853 & 533,997 & 36,717 & 4,336 & 156,187 & 10,951 \\
\hline \multicolumn{8}{|l|}{ Age } \\
\hline Age < 65 (n [\%]) & $9,954(43.5 \%)$ & \begin{tabular}{|l|}
44,753 \\
$(57.5 \%)$
\end{tabular} & $\begin{array}{l}256,270 \\
(48.0 \%)\end{array}$ & $\begin{array}{l}22,014 \\
(60.0 \%)\end{array}$ & $1,531(35.3 \%)$ & \begin{tabular}{|l|}
81,208 \\
$(52.0 \%)$
\end{tabular} & $3,836(35.0 \%)$ \\
\hline Age $>=65$ (n [\%]) & $12,933(56.5 \%)$ & \begin{tabular}{|l|}
33,100 \\
$(42.5 \%)$
\end{tabular} & $\begin{array}{l}277,727 \\
(52.0 \%)\end{array}$ & $\begin{array}{l}14,703 \\
(40.0 \%)\end{array}$ & $2,805(64.7 \%)$ & \begin{tabular}{|l|}
74,979 \\
$(48.0 \%)$
\end{tabular} & $7,115(65.0 \%)$ \\
\hline \multicolumn{8}{|l|}{ Sex } \\
\hline Male (n [\%]) & $11,769(51.4 \%)$ & $\begin{array}{l}39,911 \\
(51.3 \%)\end{array}$ & $\begin{array}{l}268,957 \\
(50.4 \%)\end{array}$ & $\begin{array}{l}18,495 \\
(50.4 \%)\end{array}$ & $2,354(54.3 \%)$ & \begin{tabular}{|l|}
81,155 \\
$(52.0 \%)$
\end{tabular} & $\begin{array}{l}10,225 \\
(93.4 \%)\end{array}$ \\
\hline Female (n [\%]) & $11,118(48.6 \%)$ & $\begin{array}{l}37,869 \\
(48.6 \%)\end{array}$ & $\begin{array}{l}264,987 \\
(49.6 \%)\end{array}$ & $\begin{array}{l}18,222 \\
(49.6 \%)\end{array}$ & $1,982(45.7 \%)$ & \begin{tabular}{|l|}
75,032 \\
$(48.0 \%)$
\end{tabular} & 726 (6.6\%) \\
\hline \multicolumn{8}{|l|}{ Comorbidities } \\
\hline Asthma (n [\%]) & $1,004(4.4 \%)$ & $5,149(6.6 \%)$ & $82,087(15.4 \%)$ & $4,922(13.4 \%)$ & $628(14.5 \%)$ & $10,497(6.7 \%)$ & $1,153(10.5 \%)$ \\
\hline $\begin{array}{l}\text { Autoimmune } \\
\text { condition (n [\%]) }\end{array}$ & $1,215(5.3 \%)$ & $5,793(7.4 \%)$ & $\begin{array}{l}136,735 \\
(25.6 \%)\end{array}$ & 4,352 (11.9\%) & $931(21.5 \%)$ & $6,387(4.1 \%)$ & $3,156(28.8 \%)$ \\
\hline $\begin{array}{l}\text { Chronic kidney } \\
\text { disease (n [\%]) }\end{array}$ & $2,622(11.5 \%)$ & \begin{tabular}{|l|}
12,016 \\
$(15.4 \%)$
\end{tabular} & $\begin{array}{l}164,710 \\
(30.8 \%) \\
\end{array}$ & $8,350(22.7 \%)$ & $1,357(31.3 \%)$ & \begin{tabular}{|l|}
24,282 \\
$(15.5 \%)$ \\
\end{tabular} & 3,958 (36.1\%) \\
\hline COPD (n [\%]) & $2,213(9.7 \%)$ & \begin{tabular}{|l|}
10,153 \\
$(13.0 \%)$ \\
\end{tabular} & $\begin{array}{l}118,421 \\
(22.2 \%) \\
\end{array}$ & $6,777(18.5 \%)$ & $1,066(24.6 \%)$ & $13,699(8.8 \%)$ & $4,641(42.4 \%)$ \\
\hline Diabetes (n [\%]) & $3,880(17.0 \%)$ & \begin{tabular}{|l|}
22,470 \\
$(28.9 \%)$
\end{tabular} & $\begin{array}{l}254,505 \\
(47.7 \%)\end{array}$ & \begin{tabular}{|l|}
12,227 \\
$(33.3 \%)$
\end{tabular} & $1,844(42.5 \%)$ & $\begin{array}{l}45,790 \\
(29.3 \%)\end{array}$ & $5,839(53.3 \%)$ \\
\hline Heart disease (n [\%]) & $5,178(22.6 \%)$ & $\begin{array}{l}22,423 \\
(28.8 \%)\end{array}$ & $\begin{array}{l}319,842 \\
(59.9 \%)\end{array}$ & $\begin{array}{l}17,185 \\
(46.8 \%)\end{array}$ & $2,634(60.7 \%)$ & $\begin{array}{l}47,198 \\
(30.2 \%)\end{array}$ & $7,421(67.8 \%)$ \\
\hline Hypertension (n [\%]) & $6,410(28.0 \%)$ & \begin{tabular}{|l|}
36,071 \\
$(46.3 \%)$
\end{tabular} & $\begin{array}{l}390,171 \\
(73.1 \%)\end{array}$ & \begin{tabular}{|l|}
21,290 \\
$(58.0 \%)$
\end{tabular} & $2,977(68.7 \%)$ & $\begin{array}{l}74,311 \\
(47.6 \%)\end{array}$ & $9,087(83.0 \%)$ \\
\hline Obesity (n [\%]) & $2,238(9.8 \%)$ & 14,878 & 191,071 & 20,188 & 1,626 (37.5\%) & 35,462 & 5,677 (51.8\%) \\
\hline
\end{tabular}




\begin{tabular}{|l|l|l|l|l|l|l|l|}
\hline & & $(19.1 \%)$ & $(35.8 \%)$ & $(55.0 \%)$ & & $(22.7 \%)$ & \\
\hline
\end{tabular}


Figure 1. Proportion of patients hospitalized with COVID-19 who underwent ECMO, tracheostomy, or dialysis, overall and stratified by age and sex. Point estimates with $95 \%$ confidence intervals (counts of less than 10 have been omitted).
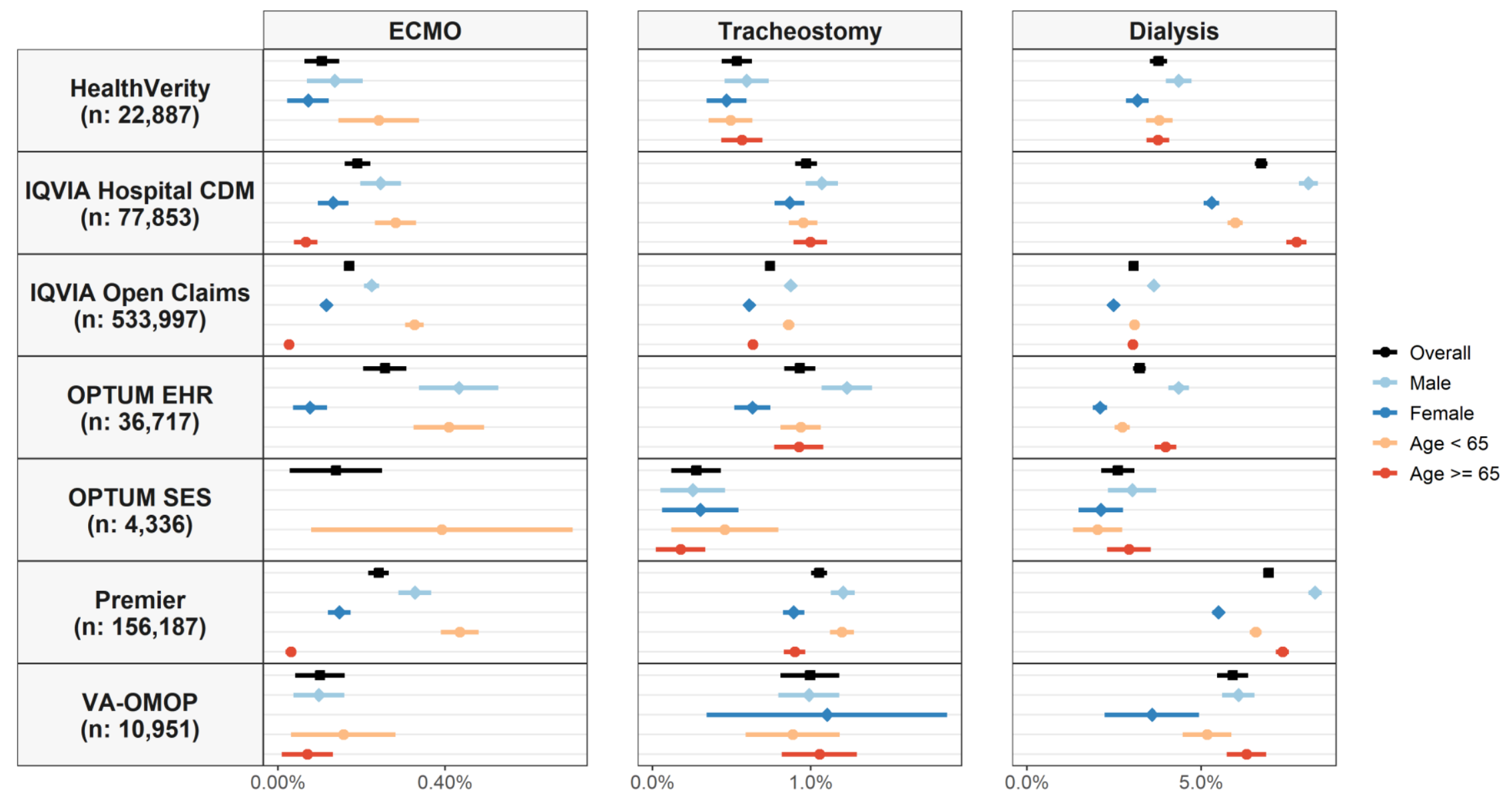

Proportion of patients undergoing intervention over 30 days from hospitalisation with COVID-19 
Figure 2. Proportion of patients hospitalized with COVID-19 who underwent ECMO, tracheostomy, or dialysis, overall and stratified by comorbidities of interest. Point estimates with $95 \%$ confidence intervals (counts of less than 10 have been omitted).
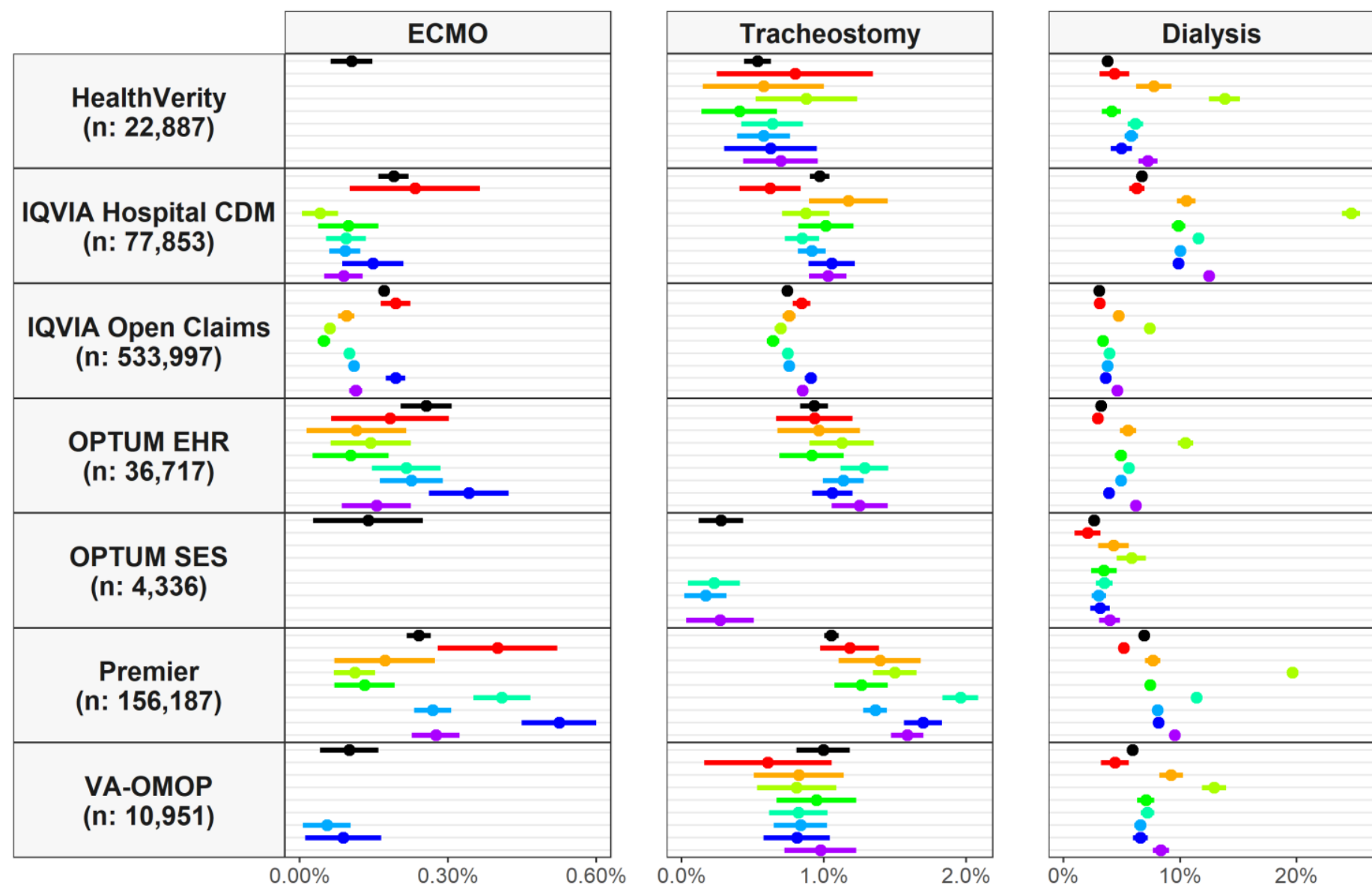

- Overall

$\rightarrow$ Asthma

- Autoimmune condition

- Chronic kidney disease

- COPD

- Heart disease

$\rightarrow$ Hypertension

$\rightarrow$ Obesity

- Type 2 Diabetes

Proportion of patients undergoing intervention over 30 days from hospitalisation with COVID-19 
medRxiv preprint doi: https://doi.org/10.1101/2020.11.25.20229088; this version posted February 12, 2021. The copyright holder for this preprint (which was not certified by peer review) is the author/funder, who has granted medRxiv a license to display the preprint in

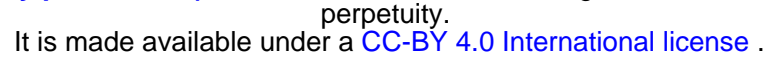

\section{Funding}

This project has received support from the European Health Data and Evidence Network (EHDEN) project. EHDEN has received funding from the Innovative Medicines Initiative 2 Joint Undertaking (JU) under grant agreement No 806968. The JU receives support from the European Union's Horizon 2020 research and innovation programme and EFPIA. This research received partial support from the National Institute for Health Research (NIHR) Oxford Biomedical Research Centre (BRC), US National Institutes of Health, US Department of Veterans Affairs, Janssen Research \& Development, and IQVIA. This work was supported using resources and facilities of the Department of Veterans Affairs (VA) Informatics and Computing Infrastructure (VINCI), VA HSR RES 13-457. The University of Oxford received funding related to this work from the Bill \& Melinda Gates Foundation (Investment ID INV016201 and INV-019257).

Personal funding included: AP-U is supported by Fundacion Alfonso Martin Escudero and the Medical Research Council (grant numbers MR/K501256/1, MR/N013468/1), WURA reports funding from the NIHR Oxford Biomedical Research Centre (BRC), Aziz Foundation, Wolfson Foundation, and the Royal College Surgeons of England, JCEL is supported by Versus Arthritis Clinical Research Fellowship (21605) and the Medical Research Council (MR/K501256/1), GH is supported by US NIH National Library of Medicine grant R01 LM006910., OTR is funded by a Sara Borrell grant from the Instituto de Salud Carlos III (CD19/00110). DPA is supported by a NIHR Senior Research Fellowship (SRF-2018-11-ST2004).

No funders had a direct role in this study. The views and opinions expressed are those of the authors and do not necessarily reflect those of the Clinician Scientist Award programme, NIHR, Department of Veterans Affairs or the United States Government, NHS, or the Department of Health, England.

\section{Ethical approvals}

All the data partners received Institutional Review Board (IRB) approval or exemption. The use of VA data was reviewed by the Department of Veterans Affairs Central Institutional Review Board (IRB) and was determined to meet the criteria for exemption under Exemption Category 4(3) and approved the request for Waiver of HIPAA Authorization. Other databases used (HealthVerity, Premier, IQVIA Open Claims, Optum EHR, and Optum SES) are commercially available, syndicated data assets that are licensed by contributing authors for observational research. These assets are de-identified commercially available data products that could be purchased and licensed by any researcher. The collection and de-identification of these data assets is a process that is commercial intellectual property and not privileged to the data licensees and the co-authors on this study. Licensees of these data have signed Data Use Agreements with the data vendors which detail the usage protocols for running retrospective research on these databases. All analyses performed in this study were in accordance with Data Use Agreement terms as specified by the data owners. As these data are deemed commercial assets, there is no Institutional Review Board applicable to the usage and dissemination of these result sets or required registration of the protocol with additional ethics oversight. Compliance with Data Use Agreement terms, which stipulate how these data can be used and for what purpose, is sufficient for these commercial entities. Further inquiry related to the governance oversight of these assets can be made with the respective commercial entities: IQVIA (iqvia.com) and Optum 
medRxiv preprint doi: https://doi.org/10.1101/2020.11.25.20229088; this version posted February $12,2021$. The copyright holder for this preprint (which was not certified by peer review) is the author/funder, who has granted medRxiv a license to display the preprint in perpetuity.

It is made available under a CC-BY 4.0 International license .

(optum.com). At no point in the course of this study were the authors of this study exposed to identified patient-level data. All result sets represent aggregate, de-identified data that are represented at a minimum cell size of $>5$ to reduce potential for re-identification.

\section{Competing interests}

All authors have completed the ICMJE uniform disclosure form, with the following declarations made: AS reports personal fees from Janssen Research \& Development, during the conduct of the study; personal fees from Janssen Research \& Development, outside the submitted work. AS is a full time employee of Janssen and shareholder of Johnson \& Johnson. SDV reports grants from Anolinx, LLC, grants from Astellas Pharma, Inc, grants from AstraZeneca Pharmaceuticals LP, grants from Boehringer Ingelheim International $\mathrm{GmbH}$, grants from Celgene Corporation, grants from Eli Lilly and Company, grants from Genentech Inc., , grants from Genomic Health, Inc., grants from Gilead Sciences Inc., grants from GlaxoSmithKline PLC, grants from Innocrin Pharmaceuticals Inc., grants from Janssen Pharmaceuticals, Inc., grants from Kantar Health, grants from Myriad Genetic Laboratories, Inc., grants from Novartis International AG, grants from Parexel International Corporation through the University of Utah or Western Institute for Biomedical Research outside the submitted work. MEM has nothing to disclose. CR is an employee of IQVIA. CB reports other from Janssen, Research and Development, outside the submitted work; and full time employee of Janssen R\&D and Johnson \& Johnson shareholder. AA reports other from Janssen, Research and Development, outside the submitted work; and full time employee of Janssen R\&D and Johnson \& Johnson shareholder. SF reports other from Janssen, outside the submitted work. AG reports personal fees from Regeneron Pharmaceuticals, outside the submitted work. She is a full-time employee at Regeneron Pharmaceuticals. This work was not conducted at Regeneron Pharmaceuticals. DM is supported by a Wellcome Trust Clinical Research Development Fellowship (Grant 214588/Z/18/Z) and reports grants from Chief Scientist Office (CSO), grants from Health Data Research UK (HDR-UK), grants from Tenovus, grants from National Institute of Health Research (NIHR), outside the submitted work. PR reports grants from Innovative Medicines Initiative, grants from Janssen Research and Development, during the conduct of the study. VS reports grants from National Science Foundation, grants from State of Arizona; Arizona Board of Regents, grants from Agency for Healthcare Research and Quality, outside the submitted work. DV reports personal fees from Bayer, outside the submitted work; and he is a full-time employee at a pharmaceutical company. GH reports grants from US NIH National Library of Medicine, during the conduct of the study; grants from Janssen Research, outside the submitted work. MAS reports grants from US National Science Foundation, grants from US National Institutes of Health, grants from IQVIA, personal fees from Janssen Research and Development, during the conduct of the study.PR reports and is employee of Janssen Research and Development and shareholder of Johnson \& Johnson. DPA reports grants and other from AMGEN, grants, nonfinancial support and other from UCB Biopharma, grants from Les Laboratoires Servier, outside the submitted work; and Janssen, on behalf of IMI-funded EHDEN and EMIF consortiums, and Synapse Management Partners have supported training programmes organised by DPA's department and open for external participants. KK reports she is an employee of IQVIA. All other authors declare no competing interests. 